Filo. y Lingüí. 6 (1 y 2): 3-23, 1980

\title{
EL ESPAÑOL DE COSTA RICA
}

\section{ESTUDIO FONOLOGICO GENERATIVO}

\author{
Jack L. Wilson \\ Universidad de Costa Rica
}

\section{CAPITULO I}

\section{INTRODUCCION}

\section{El problema}

Este estudio tiene como propósito el constatar las divergencias fonológicas del español normativo, o "modelo", en ciertas áreas escogidas de Costa Rica, y la formalización de su distribución, usando como fuente cuestionarios llenados por el investigador en entrevistas personales con 47 informantes procedentes de 24 ciudades y pueblos del pais.

Se ha pretendido (Cf. Weinreich 1954) que los estudios dialectológicos estructurales en el pasado han puesto énfasis en diferencias de distribución. Mario Saltarelli (1966) señala que, de hecho, el tema exclusivo de la dialectología estructural ha sido el de comparar inventarios fonémicos mediante "fórmulas de exhibición" que reflejan, de manera visual, diferencias y similitudes fonémicas. El actual estudio, a la vez que también exhibe representaciones comparativas de información fonológica, tratará de ofrecer una introspección hacia problemas teóricos "más profundos" relacionados con la fonología española, problemas que trascienden los limites geográficos relativamente estrechos del español de Costa Rica. La consideración de un estudio fonológico generativo dentro del marco de una teoría transformacionalista de la gramática, tal como ésta es presentada por Chomsky y Halle (1968), parece ofrecer un medio para explicar formalmente ciertos casos de epéntesis que en el pasado fueron simplemente enumerados (por ejemplo, Menéndez Pidal, Navarro Tomás), y para demostrar que existe una relación entre estos casos de epéntesis y las reglas que gobiernan la colocación del acento de intensidad en general en el español desviante. Puede demostrarse, por lo tanto, que los rasgos desviantes de formas tales como [ Rekáyda], "recaída", y
[ kanóba ], "canoa", están fonológicamente relacionados. Una parte del problema, pues, consiste en el descubrimiento y la formalización de las reglas que gobiernan este comportamiento y comportamientos parecidos.

Más concretamente, se buscan respuestas a las siguientes preguntas:

1. ¿Cuáles son la extensión de divergencia fonológica del español modelo y la distribución formal de rasgos fonológicos en las áreas más pobladas de Costa Rica?

2. ¿Es posible la formalización de los casos desviantes de epéntesis y la colocación del acento de intensidad, y de su relación entre sí?

3. ¿Existen realizaciones en el español desviante de Costa Rica de tendencias generales relacionadas con la estructura silábica que se encuentren en otras áreas donde se habla el español?

Hasta donde sepa el que esto escribe, nadie ha tratado de dar respuesta a ninguna de estas preguntas.

La primera pregunta implica cierto número de preguntas específicas (de "bajo nivel"). Por ejemplo, ¿cómo se realiza fonéticamente la secuencia $-p t-$ en diferentes áreas? Con letras que representan abreviaciones de rasgos, si hay una regla

$$
\mathrm{p} \rightarrow \mathrm{k} / \longrightarrow \mathrm{t},
$$

¿hay otras reglas del tipo

$$
\mathrm{k} \rightarrow \mathrm{X} / \mathrm{t} \text { ? }
$$

¿Dónde encontramos arcaísmos, es decir reflejos de formas protomodelo (por ejemplo, [ hyéRo ] o [ hího ] en lugar de las formas modelo [yéRo ] "hierro" o [ ího ] "hijo")?

Más adelante trataremos con más detalle la segunda pregunta.

Una respuesta afirmativa a la tercera pregunta tendería a apoyar a Amado Alonso (1945) y 
a Bertil Malmberg (1965) en lo que parece ser su tesis de que hay ciertos procesos latentes en la fonología española en general que pueden realizarse superficialmente de diferentes maneras en diferentes lugares.

Se pretende en este estudio que las 24 ciudades, representadas por 47 informantes, presentarán un cuadro de distribución fonológica geográfica en Costa Rica. Las áreas que se incluyen en el estudio son: la zona central (el valle central y lugares cercanos, el valle del Guarco, y el valle de Turrialba); la provincia de Guanacaste; lugares escogidos de la provincia de Puntarenas; una ciudad del valle de El General; y, Puerto Limón en la provincia de Limón. Las partes excluidas son: las partes norcentral y nordeste del país, que tienen poca población; la provincia de Limón, con excepción de Puerto Limón; y, la escasamente poblada región del sur. En esta última región vive la mayoría de los indígenas del país, en partes de la región se habla italiano o inglés (en una gran parte de la región también se habla inglés), una parte de la región consiste en plantaciones de la United Fruit Company, y la mayor parte de lo que queda está representada por emigrantes recientes de otras partes del país quienes se han establecido a lo largo de la carretera interamericana que hace relativamente poco se terminó de construir.

\section{Preliminarios sociogeográficos*}

Aunque Costa Rica fue descubierto el 18 de setiembre de 1502, cuando Colón llegó a la bahía de Cariarí, cerca del actual Puerto Limón, fue el último país centroamericano que se colonizó. La colonización comenzó en 1524 cuando Francisco Fernández de Córdoba (o "Córdova"), en una expedición desde Panamá, fundó la primera "villa", Bruselas, a poca distancia del Golfo de Nicoya en la parte occidental del país, entre los ríos Aranjuez y Guacimal en la actual provincia de Puntarenas. Los primeros colonos eran un número reducido de españoles que acompañaban a Fernández de Córdoba, y algunos indios traídos de la llanura de Esparza. En esta misma expedición, Fernández de Córdoba fundó la villa de Nicoya, y la Península de Nicoya quedó, hasta 1561, el único territorio de occidente que estaba completamente bajo el

* Los datos que síguen fueron tomados de Jiménez Castro (1956) y Sandner (1961). control de los españoles después de la destrucción de Bruselas en 1527 por Diego López de Salcedo, Gobernador de Honduras. En el este, Hernán Sánchez de Badajoz, adelantado y mariscal de Costa Rica por mandato de la Audiencia de Panamá, fundó, en 1540, la villa de Badajoz y el Puerto de San Marcos en el Río Tarire (ahora Sixaola). San Marcos fue el primer poblado que se estableciera en la costa del Atlántico. Hacia el norte, sobre la costa del Atlántico, Diego Gutiérrez, en 1543, fundó la villa de Santiago en la desembocadura del Río Suerre (ahora Reventazón), y a cierta distancia de la costa la villa de San Francisco. En marzo de 1561, Cavallón fundó la ciudad de Garcimuñoz a orilla del Río Ciruelas, cerca del actual poblado de Turrúcares. En el mismo año fundó la villa de Los Reyes, donde está actualmente Orotina, y el puerto de Landecho en la Bahía de Tivives, en la costa del Pacífico, y de esta manera aseguró definitivamente el dominio español sobre esta parte del país. En 1563 Juan Vásquez de Coronado fundó la ciudad de Cartago y ordenó el traslado a ese lugar de los habitantes de Garcimuñoz. Cartago se convirtió en la capital de la provincia de Costa Rica. En 1572, Perafán de Rivera ordenó el traslado de Cartago al llano de Mata Redonda (actualmente La Sabana en San José), pero dos años más tarde el gobernador interino, Anguciano de Gamboa, lo volvió a trasladar a su sitio actual en el valle del Guarco.

En 1674 a los pocos colonos que habían permanecido en la parte septentrional de la actual Puntarenas se les ordenó trasladarse a la villa de Espíritu Santo, que más tarde se llamara Esparza. A partir de 1575, frailes franciscanos comenzaron a reunir a los indios en villas en la parte central del país desde cerca de la actual Heredia en el oeste hasta Turrialba en el este.

El número de colonos españoles permaneció pequeño. En 1611 la población total de Costa Rica se dio en 15.538 personas, de las cuales 330 eran españoles (la mayoría provenientes de Andalucía, Extremadura y Castilla la Vieja), había 300 entre negros, mulatos y mestizos; los demás eran indios diezmados por la enfermedad y que en números elevados estaban emigrando de la zona central. La mayoría de los españoles vivía en Cartago. Desde 1665 hasta 1676 las incursiones de los piratas, así como las incursiones de los zambo mosquitos desde el lado norte del Río San Juan, obligaron la migración de la minúscula población que se encontraba en o cerca de la costa oriental hacia el valle 
del Guarco y el área circunvecina. En 1685, y de nuevo en 1686, piratas bajo el mando de Cook capturaron y saquearon Nicoya y Esparza, arrasando esta última, y de este modo se produjo una nueva migración hacia la zona central del país. Unos pocos españoles quedaron en Nicoya y Esparta, sin embargo, y pronto se confundieron entre los indios y los zambos. Ya para entonces la mayoría de los indios había migrado hacia el sur donde había pocos blancos, de modo que la zona central quedó casi por completo en manos de blancos, negros y mestizos. Los indios se establecieron cerca de la actual ciudad de San Isidro El General, donde permanecieron hasta 1856 , cuando de nuevo se produjo una migración obligada por blancos que buscaban tierras para fincas agrícolas y ganaderas en la región.

En 1675 los dos centros de población más grandes en Costa Rica eran Cartago, con unos 600 habitantes, y Esparta, con unos 100. Con la despoblación de las regiones costaneras y la subsiguiente concentración de la población en la zona central, surgieron otros pequeños centros de población. El primer centro importante fue en el valle de Barba, donde en 1706 se estableció una ayuda de parroquia de la de Cartago en Cubujuquí (actual Heredia). En 1775 a todos los habitantes de Aserrí y Escazú se les ordenó trasladarse a Villa Nueva (actual San José), donde se había construido una ermita. Ya en 1783 esta ciudad contaba con una población de 4.869 habitantes. En 1763 había 200 familias en Cubujuquí, y en ese mismo año se cambió el nombre a Heredia. En 1782 se construyó una ermita en La Lajuela (más tarde Villa Hermosa y ahora Alajuela), que tenía una población de 267 personas. En 1814 se inauguró oficialmente el puerto de Puntarenas, aunque éste había funcionado como tal durante una década.

Después de la migración de los indios hacia el sur, según parece ya no se incluían en los cálculos estadísticos del país. Para 1815 se calculaba que la población de Costa Rica era de 45.923 habitantes, de los cuales 38.902 vivían en la zona central (o "Meseta Central", según Jiménez Castro, pág. 33). Las cuatro ciudades principales eran San José con 11.587 habitantes, Cartago con 8.414, Heredia con 8.927, y Alajuela con 5.409.

Guanacaste aún no formaba parte de Costa Rica. Antes de alcanzar Costa Rica su independencia en 1821, la parte noroccidental de la actual Costa Rica había pertenecido a la provincia de Nicaragua.
Para el aspecto político no fue posible en 1813 elegir a la Audiencia de Guatemala un representante, esto en los últimos días de la colonia, según el Gobernador don Juan de Dios de Ayala. Fue necesario en 1820 que el Gobierno colonial adjuntara la población de Nicoya, Santa Cruz y lugares que pertenecían a Nicaragua a la provincia de Costa Rica para elegir el representante a Cortes. Ya en tiempo de la República, por medio de un plebiscito, esos lugares manifestaron su deseo de pertenecer a Costa Rica y no a Nicaragua, por lo cual el Congreso Federal centroamericano decretó en 1825 la anexión de esos territorios a nuestro país. (Jiménez Castro, 1956)

Al finalizar la época colonial, únicamente la octava parte de Costa Rica (excluyendo al Guanacaste) estuvo poblada por no-indígenas, principalmente en las cercanías de Cartago, San José, Heredia y Alajuela. En 1824, el año anterior de la anexión de Guanacaste, 54.684 personas $(83,63 \%)$ vivían cerca de estas cuatro ciudades, y 10.709 personas $(16,37 \%)$ vivían en el resto del país. A la vez, es de hacerse resaltar que estas ciudades están muy próximas entre sí.

La introducción del café desde Cuba en 1808 , el logro de la independencia en 1821, y la anexión de Guanacaste en 1825 sirvieron como estímulos poderosos para el establecimiento de nuevas ciudades y villas. El gobierno, que a su vez reconocía la necesidad de descentralizar la población de la zona central y que se esforzaba por atraer a la población hacia las costas, comenzó a dictar decretos en los cuales se hacían donaciones de terrenos a cualquier persona, de cualquier parte del país, que quisiera ir a estas áreas inhabitadas. Estas donaciones siguieron hasta el año 1927. Como resultado, se fundó la ciudad de San Ramón en 1844 , y después de 1856 fueron emigrantes, especialmente de las ciudades cerca de San José (capital del país a partir de la independencia), a San Ramón, Atenas, Palmares, Poás, Grecia, Naranjo, Barba, Santa Bárbara, San Isidro y San Rafael de Heredia, y Esparta. No obstante, aunque se extendió el área incluida en la zona central, la mayor parte de la población del país siguió siendo la del centro. En 1862 se calculaba que el 87,33\% de la población vivía en lo que se dio por llamarse la "Meseta Central", y el 12,67\% restante vivía en 
las provincias de Puntarenas y Guanacaste. No se dieron cifras de la población de la costa oriental hasta 1883 , cuando en un censo se demostró que en la ciudad porteña de Limón había 1.858 habitantes, en su mayoría extranjeros. La mayoría de los extranjeros provenían de Jamaica, mientras que los costarricenses eran de todas partes de Costa Rica, incluyendo el Guanacaste. Se había atraído una población a esta zona para trabajar en las fincas bananeras de la United Fruit Company.

Los primeros años del siglo veinte fueron caracterizados por una creciente tendencia de la migración desde el centro hacia las regiones despobladas o semipobladas, principalmente hacia el oeste, siguiendo el recién establecido Ferrocarril al Pacífico, y al noroeste hacia las minas auríferas de Abangares en el sur de Guanacaste. Después de 1934 comenzó un nuevo movimiento migratorio hacia el sur por la costa del Pacífico y hacia el valle de El General conforme progresaba la carretera interamericana y conforme se abrían nuevas plantaciones de banano, que venían a reemplazar las del Atlántico que fueron abandonadas debido a enfermedades en los bananales.

En el censo de 1950 se ven los resultados de esta migración hacia afuera partiendo de la zona central. De acuerdo con este censo, en Costa Rica había una población de 800.875 , de la cual el $44,03 \%$ habitaba la zona central.

Actualmente, se notan las siguientes tendencias migratorias, en orden de importancia decreciente:

1. Tanto hacia la zona central como hacia fuera de ella;

2. Hacia el cantón Central de San José;

3. Desde el cantón Central de San José hacia los suburbios que lo rodean;

4. Hacia el sur por la carretera interamericana hasta la frontera con Panamá;

5. Hacia el este hasta el Atlántico por la nueva carretera a Limón;

6. Inmigración desde Nicaragua a las zonas noroccidental y norcentral de Costa Rica;

7. Inmigración desde el extranjero a la región vecina a Puerto Limón; y,

8. Una pequeña inmigración desde Panamá a la región sudoccidental de Costa Rica.

La inmigración desde el exterior actualmente parece ser un factor de poca importancia (el censo de 1950 arrojó un saldo de 33.251 personas na- cidas en el extranjero, que representaba el 4,23\% de la población) si se compara con la intensa migración interna que se está efectuando. Según el censo de 1950, el $34,1 \%$ de la población vivía en cantones en que no habían nacido, y se calculaba que entre el $55 \%$ y el $65 \%$ de la población no tenía domicilio permanente (Sandner, 1961).

De lo que se ha escrito hasta el momento, hay ciertas cosas que son de interés para los propósitos de este trabajo:

1. Ya para 1675 había únicamente dos centros de población en Costa Rica (excluyendo a Guanacaste, que formaba parte de Nicaragua): Cartago, el sucesor de Garcimuñoz que se fundó en 1561, y que tenía unos 600 habitantes; y, Esparta, con unos 100;

2. Ya para 1686 Esparza había sido arrasada por los piratas, aunque sobrevivieron unas cuantas personas, de modo que Cartago quedó como único centro importante de población en Costa Rica;

3. Hasta que se produjo la anexión de Guanacaste en 1825 , los nuevos poblados que se fundaron en Costa Rica lo eran casi siempre por personas que venían de Cartago, sea directamente o de poblados que anteriormente habían sido fundados por "cartagos" (en 1824 el 83,63\% de la población vivía cerca de Cartago, San José, Heredia y Alajuela, ciudades que a su vez eran vecinas entre sí);

4. Ya para 1862 se calculó que el $87,33 \%$ de la población (incluyendo a Ganacaste) vivía en la zona central cerca de estas cuatro ciudades;

5. Nicoya ha tenido una población más o menos permanente desde 1524 , y Nicoya y el resto de Guanacaste formaba parte de Nicaragua hasta $1825 ; y$,

6. Hasta el presente ha continuado a haber inmigración de personas de Nicaragua al Guanacaste.

Con esto en mente, uno espera encontrar cierta homogeneidad de formas fonológicas en la zona central del país, y cierta homogeneidad de formas fonológicas en Guanacaste, con un número correspondiente mayor de diferencias entre estas dos regiones que internamente dentro de cada región. Es de esperarse que los patrones discursivos se establecieron desde fecha temprana dentro de cada región, y que se encuentran zonas de transición entre las dos. 


\section{Los informantes}

Con el propósito de reunir material para este trabajo, fueron entrevistadas 47 personas residentes de 24 ciudades de Costa Rica durante los meses de julio y agosto de 1969. Por lo menos una ciudad de cada una de las siete provincias de Costa Rica está representada:

\begin{tabular}{|c|c|}
\hline $\begin{array}{l}\text { Provincia de Limón } \\
\text { Puerto Limón }\end{array}$ & $\begin{array}{c}\text { - Número de informantes } \\
3\end{array}$ \\
\hline $\begin{array}{l}\text { Provincia de Cartago } \\
\text { Turrialba } \\
\text { Cartago }\end{array}$ & $\begin{array}{c}\text { - Número de informantes } \\
1 \\
3\end{array}$ \\
\hline $\begin{array}{l}\text { Provincia de San José } \\
\text { San Isidro El General } \\
\text { San José } \\
\text { Moravia }\end{array}$ & $\begin{array}{c}\text { - Número de informantes } \\
1 \\
10 \\
2\end{array}$ \\
\hline $\begin{array}{l}\text { Provincia de Heredia } \\
\text { Santo Tomás de Santo } \\
\text { Heredia }\end{array}$ & $\begin{array}{l}\text { - Número de informantes } \\
\text { o Domingo } \begin{array}{c}1 \\
2\end{array}\end{array}$ \\
\hline $\begin{array}{l}\text { Provincia de Alajuela } \\
\text { E1 Roble } \\
\text { San Pedro Poás } \\
\text { Atenas } \\
\text { Palmares } \\
\text { San Ramón }\end{array}$ & $\begin{array}{c}\text { - Número de informantes } \\
1 \\
1 \\
1 \\
1 \\
3\end{array}$ \\
\hline $\begin{array}{l}\text { Provincia de Puntarenas } \\
\text { San Miguel de Barranc } \\
\text { Parrita } \\
\text { Puntarenas }\end{array}$ & $\begin{array}{c}\text { - Número de informantes } \\
\text { ca } \\
1 \\
1 \\
5\end{array}$ \\
\hline $\begin{array}{l}\text { Provincia de Guanacaste } \\
\text { Las Juntas de Abangar } \\
\text { Cañas } \\
\text { Bagaces } \\
\text { Liberia } \\
\text { La Cruz } \\
\text { Filadelfia } \\
\text { Santa Cruz } \\
\text { Nicoya }\end{array}$ & $\begin{array}{l}\text { - Número de informantes } \\
\text { ares } \\
1 \\
1 \\
1 \\
3 \\
1 \\
1 \\
1 \\
1\end{array}$ \\
\hline
\end{tabular}

En cada caso, excepto uno (Bagaces), el informante había nacido y había pasado la mayor parte de su vida en el lugar sobre cuya habla informaba, aunque varias de las entrevistas se llevaron a cabo en otros lugares, principalmente en San José. El informante para Bagaces había nacido en Liberia, pero había pasado casi toda su vida en Bagaces. En general, los informantes eran relativamente jóvenes, de la clase media o media baja, y la mayoría había terminado la escuela secundaria. Las edades variaban desde los 16 hasta los 45 años, con una edad promedia de 25,76 años. Cada persona entrevistada sirvió como informante primario, es decir, informaba sobre su propia habla, y a cada persona que había cursado cuando menos la escuela secundaria se le pidió que sirviera como informante secundario, es decir, que informara sobre el habla de otras personas de su área, o por su propia iniciativa suministró los datos que se buscaban.

\section{El cuestionario}

Este constaba de 167 partes y fue confeccionado de tal manera que cada rubro apareciera más de una vez. Se inspiró en el Cuestionario lingüistico hispanoamericano de Tomás Navarro 3 Tomás (1945), aunque con grandes modificaciones. Se incluyeron únicamente aquellas formas fonológicas que se creyó que un hablante de español como lengua materna podría reconocer como distintivas o que por algún motivo notaría. Creemos, por ejemplo, que nada se ganaría tomando nota del hecho universal (para el español) de que la $o$ está más abierta en sílaba cerrada, como en "flor", y más cerrada en sílaba abierta, como en "rosa". En vista de que esto sucede dondequiera que se hable el español, el hablante sin conocimientos lingüísticos no la nota. Pero, por otra parte, las diferentes variedades de $r r$ a menudo son tema de conversación.

Al informante se le hacían preguntas (“¿Cómo se llama___ ?”) o se le pedía que completara oraciones ("La mamá de su mamá es su __. ."). Ciertas formas comunes se buscaron en el habla del informante fuera del cuestionario (la pronunciación de "si", "desde", etc.). Cierto número de rubros que se habían incluido en el cuestionario fueron luego excluidos debido a ciertos problemas que surgieron, y que este autor desconocía en el momento de su elaboración. Con otras formas no había desviaciones del español modelo. No había casos, por ejemplo, de [ beníl ] en lugar del modelo [ benír ], "venir". 


\section{CAPITULO II}

\section{MARCO TEORICO}

Hasta donde sepa el que esto escribe, nunca se ha llevado a cabo ningún estudio dialectal sistemático de ninguna área de Centroamérica. Stanley Robe ha hecho un estudio del español de Panamá (1960), pero este país no se considera como parte de Centroamérica. Carlos Gagini, quien tal vez sea el más representativo de los escritores costarricenses sobre su idioma, tiene un enfoque estrictamente normativo, y su texto Elementos de gramática castellana no refleja ningún estudio sistemático del español de Costa Rica. El singular estudio fonológico del español de Costa Rica, "The phonemes of Costa Rican Spanish" de Chavarría-Aguilar (1951), está basado en la pronunciación de dos personas, y, dentro de un marco estructuralista, es débil tanto por los hechos que describe como por su teoría.

Estudios pertinentes pre o no generativas de la fonología española son aquellos que tratan primordialmente de generalizaciones acerca del idioma, que dan ejemplos de formas que son desviantes del español modelo en diferentes áreas geográficas, o que dan información diacrónica de interés para un estudio principalmente sincrónico. El concepto de Amado Alonso de "sarpullido en el idioma" (1961, pág. 120) es de especial interés. Este concepto da respaldo a una de las hipótesis del estudio actual: que formas iguales, que reflejan una misma competencia, pueden actualizarse independientemente en áreas no contiguas.

Tanto Amado Alonso (1945) como Malmberg (1965) son de interés por sus tratamientos de tendencias silábicas generales en español. Saporta y Contreras (1962) han formalizado una gran parte de estos tratamientos dentro de un modelo fonológico generativo; ellos están, de hecho, entre los pocos fonólogos generativos que han tomado en cuenta la sílaba. Interesa, también, su introducción del símbolo '- ' para indicar cierta clase de linde constituyente (pág. 28), con el cual explican eficazmente por qué $w$ y $y$ (y menos eficazmente $r r$ ) no deben considerarse como entidades con estado fonémico en una descripción del español. Nosotros creemos que es posible llevar aún más lejos este concepto, y que es posible excluir también a $\tilde{n}$.

Puesto que el marco teórico para este estudio es el de la fonología generativa como éste se ha desarrollado a partir de Jakobson, Fant, et alii, especialmente pertinentes son las obras de Chomsky, Halle, Postal, Kiparsky, Keyser, Weinreich, Labov, Herzog, Saltarelli, y James Harris. También pertinentes son las obras del preestructuralista Ramón Menéndez Pidal, cuyo Manual de gramática histórica española (undécima edición, 1962) contiene ejemplos excelentes de información fonológica basada en reglas (aunque sin ordenar), y las de Tomás Navarro Tomás, cuyo Cuestionario (1945) ha sido una gran ayuda para la preparación del cuestionario para el presente estudio.

Kenneth C. Hill, de la Universidad de Michigan, elaboró específicamente para este estudio los rasgos que aquí se utilizan. En esta matriz de rasgos, no se pretende incluir todos los alófonos posibles para el español de Costa Rica, sino únicamente aquellos que los hablantes mismos pueden reconocer como significativos para la diferenciación dialectal. Por nuestra parte, no pretendemos incluir reglas del más bajo nivel que sea posible. Por ejemplo, no incluimos la regla que hace constar que la / e / de "mesa" es [ + tensa ] pero la de "miel" es [ - tensa ].

Aunque esto sea principalmente un estudio sincrónico, en vista de que estamos interesados por lo general en formas desviantes del español modelo, son pertinentes ciertas afirmaciones hechas por los gramáticos generativistas sobre ciertos cambios lingüísticos. Hemos sentido de manera muy especial la influencia de Weinreich, Labov y Herzog (1968, pág. 100), quienes presentan evidencias que demuestran que el lenguaje es un objeto que posee una "heterogeneidad ordenada". Puesto que estamos interesados en el carácter sistemático de la lengua heterogénea de una comunidad tal como a menudo lo caracterizan sus hablantes individuales, creemos que hay evidencia in el presente estudio que apoya los argumentos que ellos avanzan en el sentido de que "el dominio como el que tiene el nativo sobre estructuras heterogéneas no es un asunto de multidialectalismo o 'simplemente' de realización (performance), sino que es parte de una competencia lingüística unilingüe" (pág. 101).

Chomsky afirma en Aspects (1968, pág. 3-4) que:

Lo que concierne primariamente a la teoría lingüística es un hablanteoyente ideal, en una comunidad lingüística del todo homogénea, que sabe su lengua perfectamente y al que no 
afectan condiciones sin valor gramatical, como son limitaciones de memoria, distracciones, cambios del centro de atención e interés, y errores (característicos o fortuitos) al aplicar su conocimiento de la lengua al uso real. (Traducción de Otero, pág. 5)

Nosotros creemos que el requisito de homogeneidad, que Chomsky en este párrafo hace central, debe, cuando menos, incluir como parte del significado de 'homogeneidad' el hecho de que dentro de la competencia del oyente está la inclusión de muchas reglas optativas, con diferentes ordenamientos optativos, que lo capaciten a descriminar, además de otras cosas, entre:

1. formas que nunca ha oído y que puede o no reproducir, pero que puede entender y que acepta como naturales (es decir, posibles en su lengua) o no;

2. formas que ha oído antes, pero que puede no ser capaz de reproducir, y que acepta como naturales o no; $y$,

3 . formas que por cualquier razón puede reproducir, y que acepta como naturales o no.

Un correlativo necesario de estos tres puntos es que la persona de cierta inteligencia debe poder reconocer si una persona que exhibe ciertos rasgos en su manera de hablar es o no de su propia área dialectal, aún si la primera persona no demuestra estos mismos rasgos en su propia realización, o actuación. Esto es simplemente otra manera de decir que la competencia de una persona no puede estar caracterizada únicamente por su propia realización, sino que es necesario considerar su capacidad para descriminar entre varias variantes. Por ejemplo, en las entrevistas llevadas a cabo para este estudio se presentaba un caso típico: el informante decía que "yo siempre pronuncio [barbakóa] ("barbacoa"), pero mucha gente aquí dice [ barbakóba ]". Se aceptaron, pues, ambas formas como representativas de la comunidad de este informante, aunque la única "homogeneidad" está en la competencia del informante. En Puntarenas, cierto informante declaró que "yo pronuncio [ tŕ ], pero a menudo se oye que otros puntarenenses pronuncian [ $\mathrm{tr}$ ] ", forma ésta que el informante pudo pronunciar sólo con cierta dificultad. Tomamos, sin embargo, ambas formas para Puntarenas. En Guanacaste, por otra parte, en ningún caso quisieron los informantes aceptar [ tŕ ] como representativo del área. Para el estudio efec- tuado, pues, solamente se tomó [ tr ] para las diferentes ciudades de Guanacaste. En ciertos casos (Bagaces, Santo Tomás de Santo Domingo, etc.), los informantes eran de tan poca sofisticación que solamente se logró conseguir datos primarios. En el caso de una empleada doméstica de El Roble de Alajuela, se había observado que en una situación no controlada ella pronunciaba consistentemente [ trí ] . En la situación más o menos controlada del cuestionario, pronunciaba la forma modelo [ $\mathrm{tr}$ ] . Se incluyeron ambas pronunciaciones, y se consideró significativo el hecho de que contaba con la segunda forma como variante, o regla optativa.

Weinreich, Labov y Herzog (1968, pág. 132) dicen que:

Es cada vez mayor la evidencia proveniente de estudios sociolingüísticos controlados de que la percepción realmente está controlada por la estructura lingüística; pero es una estructura que incluye no solamente unidades definidas por una función contrastiva [ es decir, las unidades fonológicas pueden ser subfonémicas - JW ], sino también unidades definidas por su papel estilístico, y su potencia para identificar al hablante como miembro de un subgrupo específico de la comunidad.

Por esta razón, nos hemos valido de los datos que informantes individuales nos han suministrado como medio de caracterizar, aunque sea en forma parcial, los rasgos diferentes del discurso de la comunidad más grande a la cual pertenecen. Si el informante reconoce que cierta forma es parte del habla de su comunidad, aún cuando él no la use, damos por sentado que la forma en realidad se da, aunque no pretendemos que este procedimiento de un cuadro completo. Formas que en realidad se dan pueden haberse omitido de los datos debido al olvido o la ignorancia del informante, o bien porque el investigador no las supo sonsacar.

Para poder dividir a Costa Rica en áreas que se definan con la mayor claridad posible, creemos que se debería escoger conjuntos de isoglosas basándose en su potencialidad para identificar a los habitantes con ciertas comunidades lingüísticas, aunque no pretendamos hacer esto nosotros. Creemos que la selección al azar, o la no selección, de isoglosas, resultará simplemente en una red de fragmentos finamente subdividida (cf. Weinreich, 
Labov y Herzog, 1968, pág. 151). Kurath y McDavid (1961) también dan más importancia a ciertas isoglosas escogidas con el propósito de definir con más claridad los lindes dialectales. No estamos completamente de acuerdo con la crítica que hace Keyser a Kurath y MacDavid (Keyser, 1963, pág. 310) en el sentido de que Kurath y McDavid demuestran la distribución geográfica basada en mapas que han confeccionado usando datos estructurados alrededor de palabras o grupos de palabras representativos, y no usando datos que exhiban reglas individuales con su distribución geográfica. Los ejemplos que ofrece Keyser de lo que se deberia hacer parecen ser simples reglas de realización de nivel extremadamente bajo en las cuales se utiliza únicamente la sustancia fónica (es decir, especificaciones completas de rasgos redundantes) como material para dar cuenta de su relación con fonemas abstractos. Creemos que el apego demasiado estricto a este concepto de Keyser tendrá como resultado la exhibición de estratos sencillos de realización con la exclusión de posibles variantes de realización. Creemos que esto sería un error tratándose de un idioma como el español que tiene una influencia normativa ubicua.

Puesto que creemos que "una posible meta de una teoría de cambio es la de determinar el conjunto de posibles cambios y posibles condiciones para el cambio" (Weinreich, Labov y Herzog, 1968, pág. 183), no podemos estar completamente de acuerdo con la implicación de que los cambios se efectúan únicamente cuando un hablante $\mathrm{A}$ aprende una regla de un hablante B, luego la asimila y puede gradualmente comenzar a preferirla por encima de su regla anterior. Algunas veces esto parece ser cierto solamente al tratarse de la realización. Nuestros datos indican, en ciertos casos, que reglas de más alto nivel permiten realizaciones superficiales alternativas, aunque cierta alternativa puede ser preferida por sobre las demás. Como ejemplo: en el español de Costa Rica parece existir una tendencia hacia la silabicidad abierta y hacia un cambio de acento desde una vocal más alta (o cerrada) a una vocal más baja (o abierta) en hiato. Esta regla evidentemente universal (para el español) permite cierto número de posibles soluciones o soluciones parciales, como se evidencia en formas que se desvían del español modelo. Una misma persona puede a veces dar soluciones alternativas, en vez de una sola solución, y su(s) solución(es) puede(n) coincidir con soluciones similares o idénticas a que se han llegado independientemente en áreas no-contiguas (el "sarpullido de idioma" de Amado Alonso, 1961, pág. 121).

En publicación aparte, esperamos poder exhibir las isoglosas, que representan las soluciones propias de cada informante y que él identifica con las de su comunidad. Estas representan la realización real del español de Costa Rica. Pero en el presente estudio, pretendemos ofrecer una caracterización, basada en reglas, de una competencia más profunda en la cual esta realización se basa. El hecho de que, en un contexto igual, el hablante puede ofrecer soluciones diferentes para un solo problema, ial vez haga pensar que cada palabra tiene su propia historia, pero consideración del hecho de que diferentes formas superficiales pueden reflejar, para el mismo hablante, una regla de más alto nivel desmiente esto para aquellos casos, y al mismo tiempo explica por qué, por ejemplo, el mismo costarricense puede decir [ $\mathrm{ab}$ súrdo ] "absurdo", [ apsolúto ] "absoluto", y [ oghéto ] "objeto". Es solamente la realización superficial de una forma la que en ciertos casos tiene su propia historia, pero esta forma es simplemente el reflejo de una regla de más alto nivel que admite ciertas opciones. Esto es pertinente en cuanto al rechazo por parte de Keyser del uso que hacen Kurath y McDavid de palabras aisladas como representativas de grupos más amplios sujetos a los cambios condicionados, pero rechazamos la implicación de Keyser de que se debería considerar únicamente reglas de más bajo nivel (aquellas que especifican el mayor número de rasgos redundantes). Porque creemos que reglas de más alto nivel pueden ser reflejadas en realizaciones superficiales, como lo indican nuestros datos, no podemos aceptar como única base para el cambio lingüístico la oposición"arcaizante/innovadora" de Weinreich, Labov y Herzog (pág. 156). En vez de esto, una misma regla subyacente (latente) puede causar la oposición entre formas superficiales (patentes) no aprendidas que estén en competencia, tales como, por ejemplo, [ Río, Ríyo, Ríbo ] "río", [ kanóa, kanóba, kanówa ] "canoa", y [ awtoriłá(d), otoriłá(d), utoridá(d) ] "autoridad".

Aunque es posible que algunas reglas en una gramática sincrónica puedan reflejar cambios de proyección cronológica (es decir, de cambios históricos conocidos), otras pueden no tener ninguna base histórica. Como afirma Bengt Sigurd (1966, pág. 36):

Debe ser claro... que una gramática generativa sincrónica tiene como propósito la descripción de las secuencias 
permitidas del idioma y la competencia lingüistica de los que usan el idioma, y no la descripción de procesos históricos, y no es necesario que los resultados sean parecidos.

Este estudio, en lugar de tratar de demostrar cambios históricos, se concentrará más bien en señalar diferencias entre formas modelo y formas que se desvían del modelo. A través de este estudio, de manera general pero con ciertas excepciones para las cuales se establecerán protoformas, se refleja la opinión de que es posible explicar formas desviantes en términos de formas modelo latentes las cuales, de todos modos, están ubicuamente presentes en forma patente para la mayoría de los dialectos del español. Esta premisa permite una justificación para describir la forma desviante [ asékto ] "acepto", por ejemplo, en términos de la formal modelo [asépto], en vez de proceder al revés. Sin embargo, habrá que considerar, y de esa manera hacer la descripción, que hay otras formas que son reflejos de formas protomodelo, es decir, arcaísmos. La selección en cada caso será determinada por las circunstancias de las mismas reglas.

\section{CAPITULO III}

\section{DESVIACIONES DE DISTRIBUCION DEL ESPAÑOL MODELO}

Aunque el español de Costa Rica tiene un inventario fonológico (véase página siguiente) algo diferente del castellano modelo peninsular (cf. Harris, 1969), este inventario también se considera modelo en Costa Rica.

Los datos que se recogieron para este estudio del español de Costa Rica reflejan un sistema común de rasgos fonológicos formales que todos los hablantes que se entrevistaron comparten en su totalidad, pero con diferentes sistemas extensionales. Estos términos, "sistema común" y "sistema extensional", son tomados de Saltarelli (1966). Por "sistema común", se entiende la lista de fonemas, y por "sistema extensional", se entiende el sistema de distribución fonológica. Además de diferencias de distribución fonológica, en el español de Costa Rica hay ciertas desviaciones de bajo nivel no compartidas, es decir, diferencias alofónicas, con relación al español de los manuales de texto.

Para efectos de este trabajo, tomamos como sistema modelo del español de Costa Rica el que describen Otto La Porte, et alii, en su libro Introducción a la fonética española (1958).

En la mayoria de los casos, las desviaciones fonológicas del español modelo de Costa Rica son diferencias formales de distribución. Para una descripción de la distribución modelo de rasgos fonológicos en el español, seguimos a Saporta y Contreras en $A$ phonological grammar of Spanish
(1962). El análisis que hacen ellos, sin embargo, está sujeto a pequeñas modificaciones como, por ejemplo, cuando afirman que la secuencia [ - ntl- ] no ocurre en español. En Costa Rica se encuentra esta secuencia en la palabra "tepeizcuintle", aún cuando es verdad que la palabra no es de origen castizo.

Para demostrar estas diferencias de distribución, emplearemos reglas del nivel más bajo que se necesiten para el propósito de este estudio. No nos interesan, sin embargo, reglas fonológicas del más bajo nivel posible, tales como

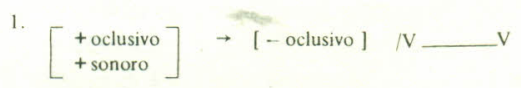

que afirma que entre dos vocales las oclusivas sonoras se convierten en fricativas. De todos modos esta regla puede no ser cierta. Presupone que las formas [ b ], [d ] y [ g ] latentes se convierten respectivamente en $[\mathrm{b}],[\sharp]$ y $[\mathrm{g}]$ en posición intervocálica. Puede haber argumentos igualmente válidos en el sentido de que sucede exactamente lo contrario: que las formas latentes $[b, d, g]$ se convierten respectivamente en [b,d,g ]. En todo caso, el asunto nos parece de poca importancia, y, sea cual sea la regla correcta, es la regla universalmente correcta para el español. 
Tampoco nos ocupamos de reglas de alto nivel que se necesitan para explicar ciertas variantes morfológicas, tales como

$$
2 . / \mathrm{k} / \rightarrow[\mathrm{s}] / \longrightarrow\left[\begin{array}{l}
+ \text { silábico } \\
- \text { posterior }
\end{array}\right]
$$

en

/eléktriko/ $\rightarrow$ [ eléktriko ]
/elektrikidád/ (or, /elektrikitate/) $\rightarrow[$ [ elektri-
sidád $].$

\section{h y w b f $\quad$ y $r$ r $\quad$ s}

Silábico
Consonántico
Oclusivo
Nasal
Alto
Posterior
Bajo
Agudo
Labial
Fricativo
Sonoro
Apical
Tenso

\section{e $\quad$ o $\quad$ a $\quad$ i $\quad$ u}

$\begin{array}{llllll}+ & + & + & + & + & \text { Silábico } \\ - & -- & - & - & - & \text { Consonántico } \\ - & - & - & - & - & \text { Oclusivo } \\ - & - & - & - & - & \text { Nasal } \\ - & - & - & + & + & \text { Alto } \\ - & + & + & - & + & \text { Posterior } \\ - & - & + & - & - & \text { Bajo } \\ - & - & - & - & - & \text { Agudo } \\ - & + & - & - & + & \text { Labial } \\ - & - & - & - & - & \text { Fricativo } \\ + & + & + & + & + & \text { Sonoro } \\ - & - & - & - & - & \text { Apical } \\ + & + & + & + & + & \text { Tenso }\end{array}$

El análisis de nuestros datos indica que la mayoría de las formas fonológicas desviadas en el español de Costa Rica, al nivel de la palabra fonológica o de más bajo nivel, pueden explicarse en términos de un número limitado de procesos que actúan sobre la sílaba. Para una descripción de la palabra fonológica en español, véase Saporta y Contreras (1962). En el presente estudio, no pretendemos abarcar más que la palabra fonológica, excepción hecha del artículo definido en plural seguido por un sustantivo en plural.

Con la excepción de ciertos cambios de bajo nivel en las reglas de especificaciones de rasgos (por ejemplo, / + nasal $/ \rightarrow[n]$ (__ \#), la mayoría de las formas desviadas en el español de Costa Rica son variantes optativas de formas modelo. Así, por ejemplo, en nuestros datos encontramos que en toda Costa Rica coexisten, como variantes optativas, las dos formas de "recaída": [ Rekaída ] y [ Rekáyda ]. La mayoría de las formas subyacentes que son diferentes de las formas modelo que aparecen en la superficie, por ejemplo los arcaísmos, también son variantes optativas de formas modelo. Así encontramos [ hedióndo ] y [ edióndo ] como variantes optativas de "hediondo".

Nuestros datos demuestran, con unas cuantas excepciones que analizaremos más tarde, que estas variantes desviadas pueden explicarse como el resultado de una reestructuración dentro de la palabra fonológica, con una tendencia hacia la silabicidad abierta del tipo $\mathrm{A}_{1} N \mathrm{NA}_{2} \mathrm{~N}$, en el cual $\mathrm{A}_{1}=$ cualquier abriente absoluto de la palabra, $\mathrm{N}=$ cualquier núcleo silábico, y $\mathrm{A}_{2}=$ cualquier abriente interno de la palabra. Posiblemente como 
ejemplos de sobrecorrección, en las formas desviadas se encuentran numerosas excepciones.

Todos nuestros datos pueden explicarse en términos de los siguientes encabezamientos principales, aunque el primero es el que comprende más aspectos.

I. Reestructuración silábica.

II. Cambios de bajo nivel en los rasgos redundantes subfonemáticos.

III. Formas subyacentes diferentes de aquellas que aparecen en la superficie en el español modelo.

IV. Misceláneo (abrientes, cerrantes absolutos de la palabra, etc.).

La reestructuración silábica desviante puede relacionarse con los siguientes procesos:

A. Cambio de acento de intensidad.

B. Cambios en la colocación de los lindes silábicos.

C. Epéntesis.

D. Cambios en los núcleos silábicos.

E. Cambios en las especificaciones de los rasgos de los cerrantes internos.

En este trabajo, nos ocuparemos principalmente de las subpartes A, B y C de I.

\section{Cambio de acento de intensidad}

Si aceptamos la previa colocación del acento de intensidad en las palabras fonológicas en español, debemos buscar una explicación para formas desviantes, tales como las siguientes:

3. 1) ataúd*: atáwd

2) Rekaída: Rekáyda

3) aógo: áwgo

4) maéstro: máystro

5) inkreible: inkréyble

6) Reír: Réyr

7) oséano: oseáno, osiáno, osyáno

8) oído: óydo

9) período: peryódo

* En todos nuestros ejemplos se sobreentiende el empleo de paréntesis cuadrados. En cada caso, se da primero la forma modelo. Cuando es necesario, se da la forma ortográfica entre comillas.
En cada caso, el acento se ha pasado de una vocal más alta en una secuencia [ VV ], en la cual [V] = cualquier vocal, a una más baja, cuando ésta no va seguida por [\#] ( = linde de palabra o de morfema). Si se acepta que este cambio del acento de intensidad es general, hay todavía lagunas en las siguientes generalizaciones, las cuales se explicarán más tarde como debidos, por lo menos en parte, a previas reglas de "sangría", es decir, reglas que eliminan todas o algunas de las representaciones que son apropiadas para una regla posterior.

En cada uno de los ejemplos de 1) a 4), el acento se ha pasado de una vocal más alta a una que la precede, la única vocal en el sistema que tiene el rasgo [ + bajo ] (es decir, [a ]), y la vocal más alta se ha convertido en paravocal, que de ahora en adelante se simbolizará como "P".

En otras palabras, encontramos que

$$
\left.\left.\begin{array}{rl}
\text { 4. } \begin{array}{l}
\text { aú } \rightarrow \text { áu } \\
\text { aó } \rightarrow \text { áo }
\end{array} & \text { ( } \rightarrow \text { áw) } \\
\text { aí } \rightarrow \text { ái } \\
\text { aé } \rightarrow \text { áe }
\end{array}\right\} \quad \text { ( } \rightarrow \text { áy }\right)
$$

En vista de que [a ] es el único segmento con el rasgo [ + bajo], podemos formalizar este cambio del acento de intensidad como en la $4 \mathrm{a}$ :

$$
\text { 4a. }[+ \text { bajo }][\text { + acento }] \rightarrow[\text { + acento }][\text { - acento }]
$$

Si adoptamos la convención de que cuando se especifica cualquier segmento con el rasgo [ + acento ] todos los demás segmentos dentro de la misma palabra tienen automáticamente el rasgo [ - acento ], 4a se reformula como en $4 \mathrm{~b}$ :

$$
\text { 4b. [ + bajo }] \rightarrow[+ \text { acento }] / \longrightarrow[+ \text { acen to }]
$$

Una segunda regla dará cuenta de los casos de cambio de acento cuando una vocal acentuada no-baja precede inmediatamente a una vocal no-acentuada baja, como:

$$
\left.\begin{array}{rl}
\text { 5. úa } \rightarrow \text { uá } \\
\text { óa } \rightarrow \text { oá }
\end{array}\right\} \quad \begin{aligned}
& \text { ( } \rightarrow \text { wá }) \\
& \left.\left.\begin{array}{l}
\text { ia } \rightarrow \text { iá } \\
\text { éa } \rightarrow \text { eá }
\end{array}\right\} \quad \text { ( } \rightarrow \text { yá }\right)
\end{aligned}
$$


Una reformulación de este cambio del acento, parakelo a 4a sería:

5a. [ + acento ] [ + bajo ] $\rightarrow[$ - acento $][$ + acento $]$

Recordando la convención sobre los acentos mencionada anteriormente, esta regla puede reformularse así:

$$
\text { 5b. [ + bajo }] \rightarrow[+ \text { acento }] /[+ \text { acento }]
$$

La regla 5 b da cuenta del cambio del acento de [oséano] a [oseáno ]. El hecho de que en nuestros datos no se encuentra ninguna otra manifestación de esta regla se tratará más tarde bajo el encabezamiento de Epéntesis.

$\mathrm{Si}$ las reglas $4 \mathrm{~b}$ y 5 b son parte de la competencia del hablante individual, pueden combinarse como en la regla 6:

6. [ + bajo $] \rightarrow[+$ acento $] /^{*} \longrightarrow[+$ acento $]$

La barra inclinada significa "en el contexto"; la raya continua es el lugar de inserción de lo que aparece inmediatamente a la derecha de la flecha; $y$, el asterisco después de la barra inclinada significa que lo que sigue puede preceder o bien seguir al cambio indicado por la flecha. Por lo tanto, esta afirma que [aú ] se convierte en [ áu ] y [úa ] en [ uá ], y que el mismo cambio ocurre cuando [a ] está en contacto con cualquier otra vocal acentuada.

En los ejemplos anteriores, "increíble, reír" y "oído" demuestran el cambio de acento desde una vocal alta a una media que precede, y la vocal alta se convièrte en P: [inkréyble, Réyr, óyło ] $\mathrm{Si}$ consideramos la no-existencia, o al menos la extrema rareza ("transeúnte", por ejemplo, existe) de las secuencias [ eú ] y [ oú ], y si dejamos a un lado por el momento el estado de $\mathrm{P}$, podemos hacer una generalización paralela a 4 arriba, como sigue:

$$
\begin{aligned}
& \text { 7. (eú } \rightarrow \text { éu) ( } \rightarrow \text { éw) } \\
& \text { (oú } \rightarrow \text { óu) ( } \rightarrow \text { ów) } \\
& \text { ei } \rightarrow \text { éi ( } \rightarrow \text { éy) } \\
& \text { oí } \rightarrow \text { ói ( } \rightarrow \text { óy) }
\end{aligned}
$$

Una reformulación de ésta, de nuevo paralela a 4a y $5 a$, es la siguiente:

7a. $\left[\begin{array}{c}+ \text { silábico } \\ - \text { alto }\end{array}\right]\left[\begin{array}{l}+ \text { alto } \\ - \text { acento }\end{array}\right] \rightarrow[+$ acento $][-$ acento $]$

Paralela a $4 \mathrm{~b}$ y $5 \mathrm{~b}$, tenemos la siguiente reformulación:

$$
\text { 7b. }\left[\begin{array}{l}
\text { + silábico } \\
- \text { alto }
\end{array}\right] \rightarrow[+ \text { acento }] /-\left[\begin{array}{l}
+ \text { alto } \\
+ \text { acento }
\end{array}\right]
$$

Para explicar el cambio de [períoło ] a [ peryódo ], se formula la siguiente regla, la cual es un fiel reflejo de espejo de 7:

8. úe $\rightarrow$ ué $(\rightarrow$ wé $)$

úo $\rightarrow$ uó $(\rightarrow$ wó)

ie $\rightarrow$ ié $(\rightarrow$ yé $)$

io $\rightarrow$ ió $\quad(\rightarrow$ yó $)$

Esta se reformula como en $8 \mathrm{a}$ y $8 \mathrm{~b}$ :

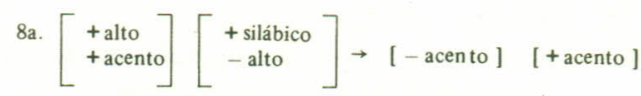

8b. $\left[\begin{array}{l}+ \text { silábicu } \\ - \text { alto }\end{array}\right] \rightarrow[+$ acento $] /\left[\begin{array}{l}+ \text { alto } \\ + \text { acento }\end{array}\right]$

Luego la regla 9 combina las reglas $7 \mathrm{~b}$ y 8 b:

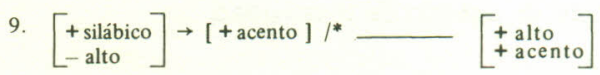

Estas reglas pueden combinarse de diferentes maneras para reflejar la realización individual del hablante, pero, si la tendencia general en el español de Costa Rica es, como aquí se pretende, la de que se pase el acento de intensidad de una vocal más alta a una más baja en cualquier secuencia / VV /,

a menos que otra regla lo impida, se llega a una regla general mediante la combinación de las reglas 6 y 9 :

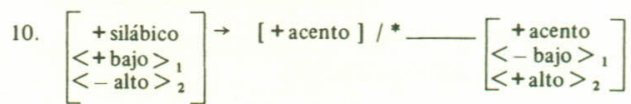

\section{Desaparición de lindes silábicos}

Si bien la regla 10 caracteriza por lo menos una faceta de la competencia de los hablantes cos- 
tarricenses del español, la regla es optativa. En toda Costa Rica se encuentran formas modelo lado a lado con formas desviadas. Como se ve en nuestros datos, la persona que dice [ Rekáyda ], "recaída", no necesariamente dice [atáwł], "ataúd". Ciertas partes componentes de la regla general se favorecen sobre las demás. Las reglas 4, 5,7 y 8 son todas componentes de la regla 10 ; sin embargo, se parece favorecer las reglas 4 y 7 a expensas de las reglas 5 y 8 . Las reglas 4 y 7 involucran un cambio regresivo del acento, mientras que las reglas 5 y 8 tratan de un cambio progresivo. Mediante las reglas 4 y 7 , el acento se pasa de una vocal más alta, en una secuencia de dos, a una precedente más baja (por ejemplo, [ aú ] $\rightarrow$ [ áu ] ), mientras que mediante las reglas 5 y 8 , el acento se pasa de una primera vocal más alta a una segunda más baja (por ejemplo, [ úa ] $\rightarrow$ [ uá ]). Por lo tanto, aunque en nuestros datos se encuentran las formas desviadas [ atáwl ] y [ Rey ], por "ataúd" y "reí", no se encuentran formas desviadas tales como [barbakoá] y [Rié ] (o [Ryé ]) para las formas modelo [barbakóa ] y [Ríe]. En su lugar, suceden otras cosas que se tratarán más adelante.

La regla 10 se hace obligatoria si a la gramática se agrega una regla previa:

\section{1. (Optativa)}

$$
[-] \rightarrow \dot{\phi} / \mathrm{V}
$$

Esta regla borra el linde silábico [ - ], como en [ Re-ka-í-ła ] $\rightarrow$ [Re-káy da ], etc. Como ésta es una regla optativa, es de esperarse que el hablante individual refleje en su realización cualquier combinación de posibles alternancias, tales como [a-ta-úd ]: [a-táwł], y [o-ídos ]: [ óy-dos ]. No hay, por lo tanto, nada inesperado si el hablante A dice [óy-dos ] y [a-ta-úd] mientras que el hablante BB dice [o-i-dos ] y [a-táwd]. Puesto que se supone una misma competencia para ambos hablantes (ambos comparten las reglas 10 y 11 ), en la superficie las cuatro formas son de esperarse, en cualquier combinación, pronunciadas por cualquier de los dos hablantes, aunque ambos hablantes pueden tener su solución preferida para cada una de las palabras individuales. Esto equivale a decir que la realización de cada hablante puede ser consistente o inconsistente. Para la ulterior solución de formas, pues, bien puede ser verdad que cada palabra tenga su propio desarrollo, pero el resultado refleja una regla, o reglas, de más profundidad en la infraestructura.
A las secuencias vocálicas / V-V / tradicionalmente se les ha llamado "vocales en hiato", y nuestra regla 11 la "destrucción del hiato".* En Saporta y Contreras (1962), se introduce un símbolo / - / para obviar la necesidad de un fonema / R / . Como ellos relacionan este símbolo con los lindes silábicos de manera únicamente indirecta, sus argumentos no son demasiado convincentes. Harris (1969) ofrece un mejor argumento al efecto de que algunos casos de [ $\mathrm{R}]$ son la manifestación fonética de una / rr / geminada de la infraestructura. En el presente estudio, no se trata de determinar su estado fonológico. Parece obvio, sin embargo, que al aceptar / - / en una transcripción fonológica plenamente especificada, sea en transcripción sistemática o en trascripción autónoma, se obvia la necesidad del fonema / $\tilde{n}$ / (o fono [ $\tilde{\mathrm{n}}]$ ), que mantienen Saporta y Contreras (1962, pág. 39). En una matriz distintiva completa del español, tal vez necesario incluir toda una serie palatal ( [ $\tilde{\mathrm{n}}],\left[\mathrm{t}^{\prime}\right]$, etc.). No queremos entrar en este detalle.

Saporta y Contreras exponen la falta de necesidad de los fonemas (autónomos?) / y / y / w / porque sus representaciones fonéticas están condicionadas por la presencia o la ausencia de un / - / precedente o siguiente. Podríamos agregar a esto que la representación fonética de "ñ" depende de la presencia o la ausencia de un $/-\mathrm{V} /$ siguiente. Por lo tanto, si se encuentran formas ortográficas como las siguientes: "inyectar, uñón, unión", y "ñato", éstas pueden explicarse en términos de sílabas internas rodeadas de $/-/$ (o, en casos como "nato", en términos de / \#/ y / - / en sílabas iniciales) como: / in-iek-tár /, / u-nión /, / u-ni-ón / y / \#iá-to /. En sus manifestaciones fonéticas, habría que mantener a [ y l (así como a [ w ] ): [ in-yek-tár ] (o [ in-ďek-tár ]), [ u-ni-ón ], y [ nyá-to ].

Debido a pares como "uñón" y "unión", que contrastan en forma mínima, habría que enmendar la regla 11 tal como se ve en el número 12 :

\footnotetext{
12. $|-| \rightarrow \phi / X V \longrightarrow V$ donde $\mathrm{XV} \neq / \mathrm{ni} /$ (optativa) (Sin embargo, $X$ puede ser igual a / - / o a $/ \# /$ )
}

\section{(')}

\footnotetext{
* En este estudio nos ocupamos únicamente del desarrollo de la palabra fonológica. Contreras (1969) habla sobre esta destrucción del hia to a través de los lindes de la palabra (/ \# /).
} 
Que para ciertas personas, o por lo menos en ciertas palabras, esta condición no rija se ve en nuestros datos en las formas desviadas tales como [ ki-nyén-tos ], "quinientos". Explicadas en términos de / - /, [ y ] y [ w ] (y sus variantes posteriores) son, ellas mismas, simplemente variantes condicionadas de / i / y / u /, respectivamente.

Esta regla parece válida cuando se trata de secuencias de dos vocales, pero con secuencias de tres o de cuatro, hay otros problemas. Las manifestaciones de [ ká-ye ] "calle", [ i-dyáy ] "idiay", [ ywé-be ] "llueve", y [yi-wí-Ro ] (o [ d $\mathrm{d}_{\mathrm{z} i-g_{w i}}$ ' ro ] ) "yigüirro", presuponen, en alguna parte de la derivación, formas latentes de [ká-i-e ], [i-di-á-i ], [i-u-é-be ], y [i-i-u-i-Ro ]. No trataremos de formular las reglas que expliquen estas formas, aunque es posible hacerlo, sino que nos limitaremos a una breve explicación.

Debemos dar como un hecho la inserción léxica de los signos de lindes silábicos de manera que, por ejemplo, [ii-uí-Ro ], y no [i-i-u-í-Ro ]

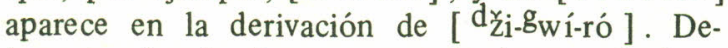
bemos, además, dar como un hecho que la desaparición de los lindes silábicos mencionada arriba es optativamente válida sólo para los casos en que se presenta una secuencia de dos vocales. En secuencias de tres vocales, encontramos tres resultados diferentes:

13. $\mathrm{V}-\mathrm{V}-\mathrm{V} \rightarrow\left\{\begin{array}{l|l}\mathrm{V}-\mathrm{PV} \\ \mathrm{PVP} \\ \mathrm{PPV}\end{array}\left\{\begin{array}{l}\text { ("calle" } \\ \text { [ká-ye ]) } \\ \text { ("idiay" } \\ \text { [i-dyáy ]) } \\ \text { ("llueve" } \\ \text { [ywébe ]) }\end{array}\right.\right.$

En cada caso, la colocación final del linde silábico (y el cambio de la vocal en $\mathrm{P}$ ) queda determinada por la altura de las vocales de la secuencia. En cada uno de los tres ejemplos de 13, la vocal acentuada es más baja que las demás. Luego, las otras vocales se convierten en $\mathrm{P}$ y las palabras se reestructuran silábicamente de modo que en una secuencia VPV el linde silábico viene antes de una $P$ seguida de otra vocal. En el caso de "yigüirro", con una secuencia de cuatro vocales, todos de la misma altura, se han agrupado en pares: / VV-VV /. Con la única excepción de "muy" [múy], parece ser un hecho universalmente verdadero para el español que la primera vocal alta de una secuencia de dos vocales altas es la que siempre se convierte en $\mathrm{P}$, por ejemplo, en "Ruiz" [ Rwís ], "guipiur" [ gi-pyúr ], etc.

\section{Tipos silábicos}

Como se afirmó anteriormente, el español de Costa Rica tiende hacia una silabicidad del tipo $A_{1} N\left(A_{2} N\right)$. Que esto sea solamente una tendencia se ve en el hecho de que el español modelo (y el no modelo) consiste de dos tipos de palabras: $\left(A_{1}\right) \mathrm{N}\left(C_{1}\right)$ en monosílabas, y $\left(A_{1}\right) \mathrm{N}\left(C_{2}\right)$ $\left(A_{2}\right) \mathrm{N}\left(C_{1}\right)$ en polisílabas. Entre $\left(C_{2}\right)$ y $\left(A_{2}\right)$ es posible agregar sílabas adicionales del tipo $-\left(\mathrm{A}_{2}\right) \mathrm{N}$ $\left(\mathrm{C}_{2}\right)$-. Los útiles abreviatorios pueden definirse como sigue:

$A_{1}$, que puede o no darse, es cualquier abriente inicial de la palabra fonológica;

$\mathrm{A}_{2}$, que puede o no darse, es cualquier abriente interno de la palabra fonológica;

$\mathrm{C}_{1}$, que puede o no darse, es cualquier cerrante final de la palabra fonológica;

$\mathrm{C}_{2}$, que puede o no darse, es cualquier cerrante interno de la palabra fonológica; $y$,

$\mathrm{N}$, de las cuales en toda palabra fonológica tiene que haber por lo menos una, es cualquier núcleo.

De acuerdo con la descripción de Saporta y Contreras, los abrientes (onsets) y los cerrantes (codas) son aquellos segmentos potenciales que contienen el rasgo [ - silábico ], hecha la salvedad que los segmentos [ $\mathrm{w}$ ] y [ y ], representados por $\mathrm{P}$, forman parte del núcleo en una secuencia $-\mathrm{A}(\mathrm{P}) \mathrm{V}(\mathrm{P}) \mathrm{C}-$, en la cual $\mathrm{V}=$ cualquier segmento con el rasgo [ + silábico ], es decir, una vocal.

La regla 12 optativamente elimina / - / bajo ciertas condiciones. Sin embargo, más tarde surgen casos, como resultado de la aplicación de otras reglas, que violan el tipo silábico básico $\mathrm{ANC}-$. Como resultado, se establece la convención de que cuando ocurre una violación, si entonces (o más tarde) no opera otra regla, se reintroduce / - /, en cualquier parte de la derivación y cuantas veces sea necesario. Esta regla de reajuste de lindes silábicos forma parte de las reglas de redundancia del idioma, no solamente de un dialecto en particular. $\mathrm{Si}$ se menciona esto ahora, es porque $\mathrm{P}$ algunas veces forma parte del núcleo, y otras veces es el abriente o el cerrante de la sílaba. Se da el caso de que al perderse el abriente de sílaba en una palabra del tipo $\mathrm{VP}-(\mathrm{A}) \mathrm{V} \rightarrow \mathrm{VP}-\mathrm{V}$, mediante esta convención la palabra se reestructura como $\mathrm{V}-\mathrm{PV}$. La regla es: 
14. Regla de reajuste de lindes silábicos (obligatoria en alguna parte de la derivación:

$$
\mathrm{P}-\mathrm{V} \rightarrow-\mathrm{PV}
$$

La $\mathrm{P}$ en sí es producto de una regla que contiene cuando menos tres partes:

\section{Regla de $\mathbf{P}$ (obligatoria):}

a)

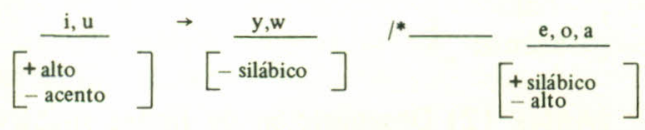

b)

$$
\left[\begin{array}{l}
\text { e, bajo } \\
- \text { acento }
\end{array}\right] \rightarrow \frac{\mathrm{y}, \mathrm{w}}{[- \text { silábico }]} \quad /^{*}-\frac{\mathrm{a}}{[+ \text { bajo }]}
$$

c)<smiles></smiles>

("Muy" [ múy ] es una excepción de c).) Nótese que c) es en realidad simplemente parte de una generalización más amplia:

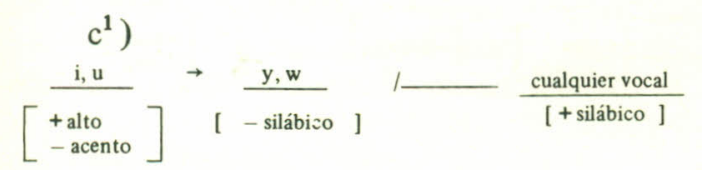

lo cual está también parcialmente incluido en a).

La regla 15 es obligatoria después de la aplicación de la 12 (pero es vacía si no se aplica la 12), $\mathrm{y}$ afirma que cualquier vocal no-acentuada y que no sea baja se convierte en $\mathrm{P}$ en la misma sílaba con otra vocal, esté o no ésta acentuada. Si se aplican las reglas 12,10 y 15 , en ese orden, se alcanzan los resultados deseados:

$\begin{array}{lcc}\text { "ataúd" } & \text { "Europa" } & \text { "hueso" } \\ \text { a-t-a-úd } & \text { e-u-ró-pa } & \text { u-é-so } \\ \text { a-taúd } & \text { eu-ró-pa } & \text { ué-so } \\ \text { a-táud } & - & - \\ \text { a-táwd } & \text { ew-ró-pa } & \text { wé-so }\end{array}$

La regla 10 es vacía para "Europa" y "hueso". La aplicación de estas reglas también convierten [i-é-lo ] "hielo" en [ yé-lo ]. Como también se encuentran las formas [ $\mathrm{g}_{\mathrm{wé}}$-so] y [dyé-lo ] (así como [ ď̌é-lo ]), se necesita otra regla posterior:

16. Endurecimiento de P (optativa):

$$
\begin{aligned}
& y \rightarrow d_{y} \\
& w \rightarrow g_{w}
\end{aligned}
$$

Esto se formaliza así:

$\left[\begin{array}{l}- \text { silábico } \\ + \text { alto }\end{array}\right] \rightarrow[+$ consonántico $] \quad\{\#\}$

Para [ ď̌é-lo ], necesitamos una regla:

17. Africación (optativa):

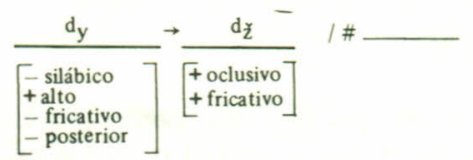

\section{Cambios en los núcleos silábicos}

La regla 15 convierte todas las vocales no-bajas en $\mathrm{P}$, pero no explica las siguientes variantes:

$$
\begin{aligned}
& \text { almoáda } \rightarrow \text { almuáła (en contraposición a } \\
& \text { peór } \rightarrow \text { piór "peor" } \\
& \text { poéta } \rightarrow \text { puéta "poeta" } \\
& \text { féo } \rightarrow \text { féu "feo" } \\
& \text { poás } \rightarrow \text { puás "Poás" } \\
& \text { toáya } \rightarrow \text { tuáya "toalla" }
\end{aligned}
$$

No se ha aplicado la regla 12 en estas palabras, con el resultado de que se mantiene a las dos vocales en contacto en cada caso como núcleos separados, pero se ha elevado la vocal central no-acentuada:

\section{Regla de elevación (optativa):}

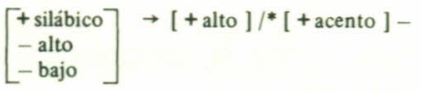

Si se aplican las reglas en el orden $12,15,18$, se obtienen todos los resultados deseados: 
$\begin{array}{lllll}\text { 12. } & \text { al-mo-á-da pe-ór } & \text { po-é-ta fé-o po-ás to-á-ya } \\ \text { 15. al-moá-da peór } & \text { poé-ta féo poás toá-ya } \\ \text { 15. } & \text { al-mwá-da pyór pwé-ta féw pwás twá-ya }\end{array}$

Como la 12 es optativa, y la 15 puede aplicarse únicamente después de la 12 , si no se escoge la 12 al aplicarse la 18 tenemos los resultados:

18. al-mu-á-da pi-ór pu-é-ta fé-u pu-ás tu-á-ya

La regla 18 eleva las vocales no-acentuadas que inmediatamente preceden o siguen a una vocal acentuada. Pero debemos también dar cuenta de las siguientes variantes:

$\begin{array}{lll}\text { polisía } & \rightarrow \text { polesía } & \text { "policia" } \\ \text { teniénte } & \rightarrow \text { tiniénte } & \text { "teniente" } \\ \text { merkádo } & \rightarrow \text { merkádu } & \text { "mercado" } \\ \text { kaye } & \rightarrow \text { kayi } & \text { "calle" } \\ \text { indibídwo } & \rightarrow \text { endebidwo "individuo" }\end{array}$

Parece ser que hay una vacilación entre [i ] y [ e ] por una parte, y entre [o ] y [ u ] por otra, en circunstancias que son diferentes de las de la regla 18. En ciertos casos se ha bajado una vocal alta, y en otros se ha elevado una vocal central. Es posible formalizar esto mediante la regla siguiente:

19. $\left[\begin{array}{l}\alpha \text { alto } \\ - \text { bajo } \\ - \text { - acento }\end{array}\right] \rightarrow[-\alpha$ alto $]$

( [ $\alpha]$ significa $[+]$ o $[-]$, y $[-\alpha]$ tiene el valor opuesto de $[\alpha])$.

Esta regla obvia la necesidad de la regla 18 en vista de que ahora la incluye.

En la forma en que está presentada, la regla 19 es una regla de libre contexto. Ciertos hablantes, sin embargo, a veces parecen limitar su aplicación a la final en la palabra. Por lo tanto, para estos hablantes habría que reformular la regla agregándole el contexto:

$19 \mathrm{a}$. \#

Entonces, para captar la generalización, la forma de la regla debe ser:

20. Regla para vocales no-acentuadas (optativa): $\left[\begin{array}{l}\alpha \text { alto } \\ - \text { bajo } \\ - \text { acento }\end{array}\right] \rightarrow[-\alpha$ alto $]($

En este punto, la lista de reglas se ha reducido a las siguientes seis:

21. (Antes 20) Regla para vocales no-acentuadas (optativa):

$\left[\begin{array}{l}\alpha \text { alto } \\ - \text { bajo } \\ - \text { acento }\end{array}\right] \rightarrow[-\alpha$ alto $]\left(/ \_\#\right)$

22. (Antes 12) Desaparición de lindes silábicos (optativo):

$$
\begin{aligned}
& /-/ \rightarrow \phi / \mathrm{XV} \_\mathrm{V} \text { donde } \mathrm{XV} \neq / \mathrm{ni} / \\
& \mathrm{y} \text { donde no hay más de tres vocales en } \\
& \text { contacto. Si } \mathrm{V}-\mathrm{V}-\mathrm{V}-\mathrm{V} \text {, entonces } \rightarrow \\
& \\
& \mathrm{VV}-\mathrm{VV} \text {. (Posteriormente, VV-VV } \\
&\rightarrow \mathrm{PV}-\mathrm{PV}) .
\end{aligned}
$$

23. (Antes 10) Regla de cambio de acento de intensidad (obligatoria):

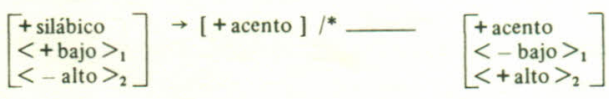

24. (Antes 15) Regla de P (obligatorio):

a)

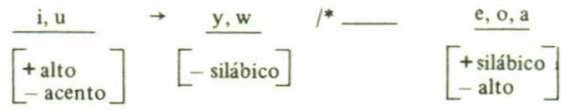

b)

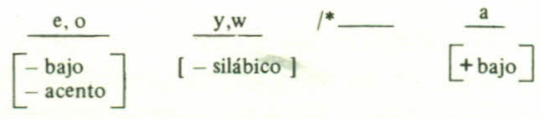

c)

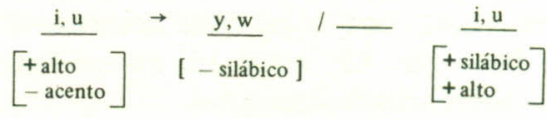

25. (Antes 16) Endurecimiento de P (optativo):

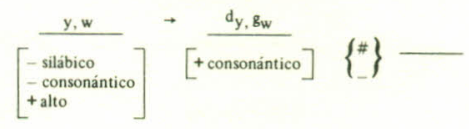


26. (Antes 17) Africación (optativo):

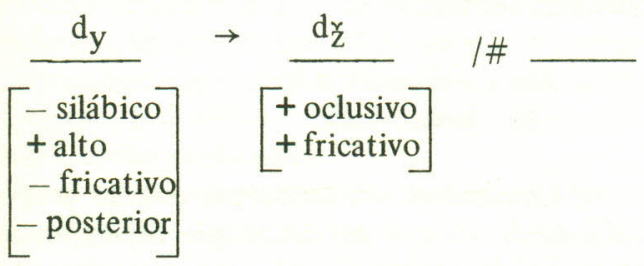

Veamos ahora algunas muestras de derivaciones con las reglas tal como están ordenadas actualmente. En los casos en que una regla es optativa, se ha hecho una selección arbitraria a favor de aquella opción que se refleja en el resultado final de los datos:

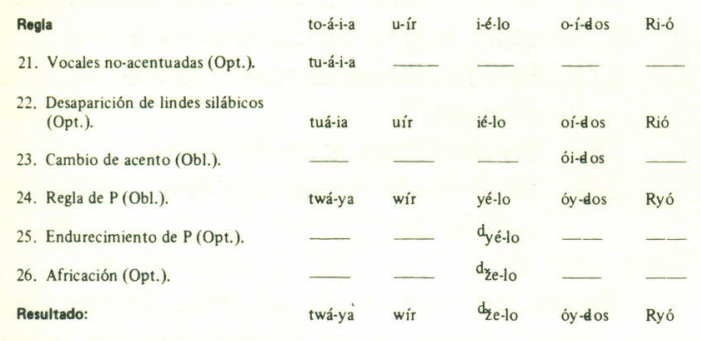

Si vemos otros ejemplos:

Regla po-ás a-o-gár u-é-so mer-ká-do

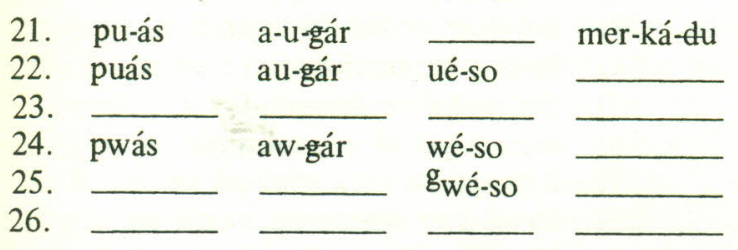
21. en-de-bídu-o ká-
22. en-de-bí-duo kái
23.
24. en-de-bí-dwo káy
25.
26.

\section{Resultado:}

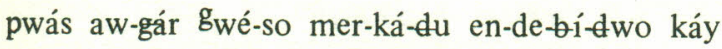

Una selección diferente para la regla 21, para $e n-d e-b i-d u-o$, resultará en la forma constatada [en-di-bídwo]. Otra selección en la regla 21 daría:
21. en-di-bí-do-o o bien in-di-bí-do-o
22. en-di-bí-doo in-di-bí-too

La adición de una sétima regla a la lista dará la monoptongación que resulta:

\section{Monoptongación (optativa):}

$$
[+ \text { silábico }]_{1} \rightarrow \phi / *[+ \text { silábico }]_{1}
$$

Después de la aplicación de esta regla, los resultados finales son [en-di-bí-do] o [in-dibí-do ], ambos constatados. Más tarde se explicará por qué esta regla es optativa. dará:

La aplicación de las reglas a otras palabras ka-nó-a

21.

22.

23. ka-noá

24. ka-nwá

25.

26.

27.

Resultado: *ka-nwá

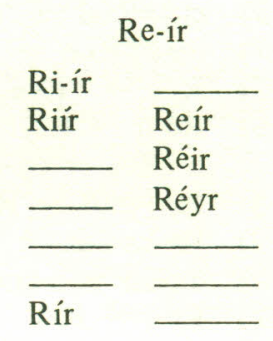

Rir Réyr
Como se ha señalado, no todas las opciones posibles (de acuerdo con las reglas) se reflejan en los resultados finales de los datos; por lo tanto, se presupone que por lo menos una característica del español de Costa Rica está representada por la suma de aquellas opciones que se han tomado.

El hecho de que las reglas predicen una forma [ ka-nwá ] inexistente es de especial interés para la próxima parte de este trabajo. Las otras formas están registradas.

Ciertas formas desviadas que se encuentran en los datos, por ejemplo [le-é, tra-é, ka-é ], en lugar de las formas modelo [ lé-e, trá-e, ká-e], posiblemente se expliquen como resultado de un esfuerzo por parte del hablante de impedir la acción de algunas de las reglas dadas arriba, especialmente las reglas 24 y 27 . Puede darse el caso de que el hablante concientemente trate de mantener las dos sílabas, y por lo tanto no escoja la regla de desaparición de lindes silábicos. Como manera de reformar la polisilabicidad, el acento se pasa a la vocal temática. Hay, por supuesto, otras posibles explicaciones: estas formas, todas ellas formas verbales, pueden reflejar la influencia de la forma 
de "vos", la de "nosotros", y la forma del infinitivo.

\section{Epéntesis}

Previamente en la regla 23 no se impusieron restricciones a las vocales que preceden inmediatamente a / \#/, aunque parece ser que en el español de Costa Rica el acento de intensidad nunca se pasa a una vocal final delante de / \#/. Se deben considerar, por lo tanto, las lagunas que se encuentran en la aplicación de esta regla. La plena aplicación de esta regla generaría, en última instancia, formas tales como las siguientes:
1) ka-nó-a $\rightarrow$ *ka-nwá
2) bar-ba-kó-a $\rightarrow$ *bar-ba-kwá
3) el\#\#Rí-o $\rightarrow$ *el\#\#Ryó
4) me\#\#Rí-o $\rightarrow$ *me\#\#Ryó
5) Rí-e $\rightarrow$ *Ryé
6) Re-ír $\rightarrow$ Réyr
7) o-í-dos $\rightarrow$ óy-dos
8) Re-i-mos $\rightarrow$ Réy-mos
9) Re-ka-í-da $\rightarrow$ Re-káy-da
10) a-t-úd $\rightarrow$ a-táwd
11) Re-i $\rightarrow$ Réy
12) in-kre-í-ble $\rightarrow$ in-kréy-ble

Las cinco primeras formas no están registradas, y se cree que no ocurren en las áreas que se describen. Todas ias otras formas están registradas.

La decisión de aplicar la regla optativa 21, últimamente resultaría en la generación de las siguientes formas:
13) a-Ré-e $\rightarrow$ *a-Réy
14) Ri-ó $\rightarrow$ *Re-ó
15) al-mo-á-da $\rightarrow$ al-mu-á-da, al-mwá-da
16) po-ás $\rightarrow$ pwás
17) to-á-i-a $\rightarrow$ tu-á-ya, twá-ya
18) ka-ká-o $\rightarrow$ ka-káw
19) bal-dí-o $\rightarrow$ bal-díw

De estas formas, solamente las dos primeras no están registradas, aunque es posible que ocurran.

La aplicación de la regla optativa 22 resultará últimamente en las siguientes formas, todas ellas registradas:

20) des-tru-ír $\rightarrow$ des-trwír

21) u-ír $\rightarrow$ wír

22) Ri-ó $\rightarrow$ Ryó
La aplicación de la regla 27 produce las siguientes formas:

23) a-Ré-e $\rightarrow$ a-Ré

24) le-ér $\rightarrow$ lér

Quedamos, sin embargo, con un grupo misceláneo de formas desviadas que tienen en común el hecho de contener, cada una, un segmento adicional que no aparece en el español modelo.

Los siguientes probablemente son reflejos de formas protomodelo, es decir, son arcaísmos:

25) ham-bri-én-to forma modelo: am-brién-to

26) huír (y otras variantes que comienzan con [ $\mathrm{h}$ ]) forma modelo: u-ír

27) hyé-Ro forma modelo: yé-Ro ("hierro")

28) hú-mo forma modelo: ú-mo

29) he-di-ón-do forma modelo: e-di-ón-do

No es tan fácil explicar otras formas desviadas como arcaísmos; más bien parecen haber adquirido un segmento epentético:

30) in-kre-í-ble $\rightarrow$ in-kre-dí-ble

31) ka-ká-o $\rightarrow$ ka-ká-do, u

32) ka-ka-i-to $\rightarrow$ ka-ka-dí-to,u

33) bal-dí-o $\rightarrow$ bal-di-do, u

34) ba-sí-o $\rightarrow$ ba-sí-do, u

35) des-nú-ka $\rightarrow$ des-nún-ka

36) men-di-gár $\rightarrow$ men-din-gár

37) a-tro-pé-ye $\rightarrow$ a-trom-pé-ye

38) ka-nó-a $\rightarrow$ ka-nó-wa, ka-nú-wa, ka-nó ba

39) bar-ba-kó-a $\rightarrow$ bar-ba-kó-wa, bar-ba-kúwa, bar-ba-kó-ba

40) (el) Rí-o $\rightarrow$ Rí-yo, Ríbo

41) (me) Rí-o $\rightarrow$ Rí-yo

42) Re-ír $\rightarrow$ Re-yír

43) Rí-e $\rightarrow$ Rí-ve

44) Re-í $\rightarrow$ Re-yí

45) Ri-ó $\rightarrow$ Ri-yó, Re-yó

46) o-í-dos $\rightarrow$ o-yi-dos

47) a-Ré-e $\rightarrow$ a-Ré-ye

48) le-ér $\rightarrow$ le-yér

49) al-mo-á-da $\rightarrow$ al-mo-wá-da

50) po-ás $\rightarrow$ po-wás, pó-was, pu-wás

51) to-á-ya $\rightarrow$ to-wá-ya

52) des-tru-ír $\rightarrow$ des-tru-yiŕ

53) u-ír $\rightarrow$ u-yír, u-wír 
Incluimos el número 30 en la lista simplemente como una rareza que no podemos explicar. Cada informante que reconoció la palabra en esta forma mencionó que se la había oído a niños. Si esto es cierto, la forma es difícil de explicar como arcaísmo o como anglicismo.

En el cuestionario preparado para conseguir los datos que formaron la base de este trabajo, la pregunta relacionada con 32) estaba mal formulada, con el resultado de que para algunos informantes la pregunta puede haber resultado confusa. Muchos informantes no conocían la palabra representada por 33), pero tanto 33) como 31) y 34) probablemente son urbanismos basados en una analogía hecha por su parecido con formas del participio pasado.

Las formas 35$)-37$ ) son ejemplos de nasales epentéticos homorgánicos, y resultan de una regla:

\section{Optativo:}

$$
\phi \rightarrow[+ \text { nasal }] / V \longrightarrow \text { (más otras con- }
$$

Que ésta no sea una regla favorecida en el español de Costa Rica se ve en el hecho de que de las cinco preguntas incluidas en el cuestionario sobre este proceso, únicamente una, la 36), recibió una respuesta favorable. La número 36 ( [ mendingár ] ) es bastante común en todas partes del país. Ni un solo informante quiso aceptar la forma [ čum-pár ] por la forma modelo [ ču-pár ] ("chupar"), ninguno aceptaba la forma [ men-dín-go ] por la forma modelo [ men-di-go ] ("mendigo"), aunque un solo informante citó la forma 37), y dos informantes citaron la 35). Probablemente sea mejor considerar la número 36) como forma desviada del vocabulario en vez de una desviación fonológica. Por lo tanto, excluimos la regla $28 \mathrm{de}$ nuestro estudio.

Las restantes formas, de 38) a 53), presentan un tipo de epéntesis mucho más frecuente en el español de Costa Rica. En cada una de estas formas, a la palabra se le ha agregado uno de tres segmentos epentéticos: [ b ], [w ] o [ y ]. En algunos casos, se encuentran segmentos epentéticos alternativos para la misma palabra.

A continuación se presenta una lista de los segmentos epentéticos, y de alternativas epentéticas, que ocurren en estas formas, con el número de la palabra debajo de la forma particular en que se manifiesta esa clase de epéntesis. No hay ejemplos de solo [ $b$ ] ni de las variantes [ $b, w, y$ ] para

\begin{tabular}{|c|c|c|c|c|}
\hline b, w & $b, y$ & $\mathrm{w}, \mathrm{y}$ & w & $y$ \\
\hline 38) & 40) & 53) & 49) & 41) \\
\hline 39) & & & 50) & . \\
\hline & & & 51) & . \\
\hline
\end{tabular}
la misma palabra:

En los 16 ejemplos:

$\begin{array}{ll}{[y]} & \text { aparece } 11 \text { veces } \\ {[\mathrm{w}]} & \text { aparece } 6 \text { veces } \\ {[\mathrm{b}]} & \text { aparece } 3 \text { veces }\end{array}$

La manifestación de [y ] parece ser más frecuente que [w] y [b] juntos. Con base en el número de lugares de manifestación por forma epentética, sin embargo, los resultados son algo diferentes:

\section{Forma}

Número de lugares donde ocurre

kanówa, kanúwa 4

kanóba 10

barbakówa, barbakúwa 4

barbakóba $\quad 10$

(el) Ríyo

(el) Ribo

(me) Ríyo

Reyír

Ríye

Reyi

Riyó, Reyó 6

oyídos 3

aRéye 2

leyér 1

almowáda 26

powás, pówas, puwás $\quad 16$

towáya, tuwáya 26

destruyír 4

(h)uyír 10

uwir 23

En estos ejemplos:

[y ] aparece 43 veces

[w ] aparece 99 veces

[b] aparece 21 veces 
Esto parece indicar que en el español de Costa Rica una [ w ] epentética (y [ b ] si ésta es derivada de $[\mathrm{w}]$ ) es más frecuente que una [y ] epentética.

La P epentética se introduce mediante la regla siguiente:

29. Regla de generación de P (optativa):

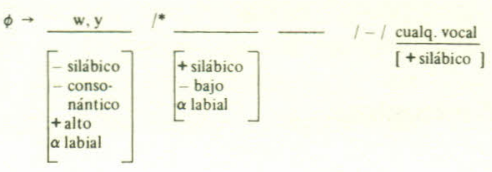

Esta regla afirma que una $\mathrm{P},[\mathrm{y}] \mathrm{o}[\mathrm{w}]$, se genera optativamente entre dos vocales cuando ambas no son [ + bajo ], es decir, no se genera $P$ entre [ a__ a ]. Si una de las vocales es [ +labial ], es decir, [ u ] u [o ], se genera [w ] . Si una de las vocales es [ - labial ], es decir, [ i ] o [e ], se genera [y ]. Si una de las vocales es [ + labial ] y la otra es [ - labial ], cualquier de las dos puede generarse. En vista de que varían las manifestaciones superficiales de la regla, por ejemplo tanto [ (h)uwír ] como [ (h)uyír ] ("huir") ocurren, "me" [ Ríbo ] no ocurre pero "me" [ Ríyo ] sí ocurre, es necesario dar las partes componentes de la regla:

\section{9a. Optativa:}

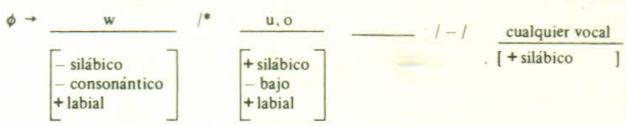

29b. Optativa:

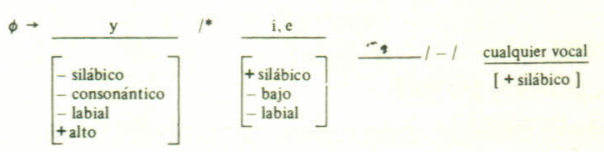

Cuando ambas manifestaciones de $\mathrm{P}$ ocurren en palabras como "huir", es porque el informante ha escogido la regla general 29. Cuando ocurre únicamente [(h)uwír ], la regla 29a se ha ordenado con respecto a la regla $29 \mathrm{~b}$ de la manera que se ve arriba. El ordenamiento al revés, es decir, $29 \mathrm{~b}$ antes de 29a, quita las condiciones para la operación de 29a, y solamente se genera [ (h)uyír ] .
La regla 29 debe ordenarse antes de la regla 23 , porque ésa quita todas las condiciones sobre las cuales ésta puede operar. Esta regla 29, que es un ejemplo de regla de "sangría", desempeña una doble función: impide el cambio de acento de intensidad y mantiene el número de sílabas de la forma modelo. La epéntesis se demuestra, muy lejos de ser un fenómeno arbitrario del español, como la manifestación de un proceso importante tendiente a mantener intacta la palabra, si bien la reestructura como ANAN, o sea, el tipo silábico preferido en la palabra polisilábica.

La regla 29 (a 29b) coloca una P en la misma sílaba con la vocal que determina su forma final, de acuerdo con el rasgo $+o-[$ labial ] de la vocal determinante. Esto puede resultar en la secuencia imposible VP-V. Cuando esto sucede, por convención se reestructura automáticamente esta secuencia como V-PV.

Para formas alternativas, tales como [ (h)uw-ír $\rightarrow$ [ (h)u-wír ]: [ (h)u-yír ], no hay razón aparente de por qué se escoge una con preferencia a la otra. Parecen ser casos de una simple identificación de la $\mathrm{P}$ epentética con una u otra vocal, de cualquier lado de $/-\mid$. Una vez hecha la selección, sin embargo, hay indicios de una correlación entre el acento y la forma final de la $\mathrm{P}$. Consideremos las siguientes formas:

$$
\begin{gathered}
\mathrm{P} \rightarrow[\text { b }] \text { (el) Ri-Po: Ríbo "el río" } \\
\text { ka-nóP-a: Ka-nó-ba "canoa" } \\
\text { bar-ba-kóP-a: bar-ba-kó-ba "bar- } \\
\mathrm{P} \rightarrow[\text { w] toP-áya: to-wá-ya "toalla" } \\
\text { (h)uP-ír: (h)u-wír "huir" } \\
\text { al-moP-á-da: al-mo-wá-da "almo- } \\
\text { poP-ás: po-wás "Poás" hada" }
\end{gathered}
$$

En los primeros ejemplos, $\mathrm{P} \rightarrow[\mathrm{b}]$, encontramos una $[b]$ epentética inmediatamente después de una vocal acentuada, mientras que en los últimos ejemplos, $\mathrm{P} \rightarrow[\mathrm{w}]$, encontramos una [ $\mathrm{w}$ ] inmediatamente delante de una vocal acentuada. La forma [ Ríbo ] alterna con [ Rí-yo ], pero [ka-nó-ba ] y [bar-ba-kó-ba ] alternan con [ ka-nó-wa ] y [ bar-ba-kó-wa ] (y [ ga-rú-ba ] alterna con [ ga-rú-wa ] "garúa"). Las formas como [ to-wá-ya ], sin embargo, no alternan con * [ to-bá-ya ]. Parece ser que es el acento de intensidad el factor determinante. Necesitamos, pues, una regla que cambie [ $\mathrm{w}]$ por [ $\mathrm{b}]$ : 
30. Endurecimiento labial:

$$
\left[\begin{array}{l}
- \text { silábico } \\
\text { - consonántico } \\
+ \text { labial }
\end{array}\right] \rightarrow[+ \text { consonántico }] /\left[\begin{array}{l}
\alpha \text { labial } \\
+ \text { acento }
\end{array}\right]-
$$

Optativo si $\alpha=+$

Obligatorio si $\alpha=-$

La regla indica, en estos ejemplos, que [ $b$ ] se deriva de [w]. La forma [Ríbo] debe haber pasado por una etapa * [ Rí-wo ], y para palabras de este tipo la regla aparentemente es obligatoria.

$\mathrm{Si}$ esto es cierto, y aunque hay excepciones, esto puede introducir un poco de luz sobre el problema de por qué, en nuestros datos, es más frecuente "el" [ Rí-yo ] que "el" [ Rí-bo ], y por qué no hay ejemplos de "me" [ Ríbo]. Estos ejemplos parecen evidenciar que mientras el acento no es el factor dominante en la determinación de la forma de la epéntesis, es, sin embargo, un factor que hay que considerar como tendiente a atraer la $\mathrm{P}$ epentética hacia la sílaba acentuada y que tiene por lo menos alguna influencia sobre su forma final.

También, si esto es cierto, las siguientes palabras tendrían las siguientes estructuras de bajo nivel en alguna parte de su derivación, más alta que en la manifestación superficial. De primero se da la forma modelo, y de último la manifestación superficial:

\begin{tabular}{|c|c|c|}
\hline (el) Ri & $\rightarrow$ RiP-o & (= Ríy-o) \\
\hline$(\mathrm{me}) \mathrm{R}$ & $-0 \rightarrow$ RiP-o & (= Riy-o) \\
\hline Re-ír & $\rightarrow$ Re-Pír & (= Re-yír) \\
\hline $\operatorname{Re}-1$ & $\rightarrow$ Re-Pí & $(=R e-y i ́)$ \\
\hline Rí-e & $\rightarrow$ RiP-e & (= Riy-e) \\
\hline (h)u-ír & $\rightarrow$ (h)u-Pír & (= (h)u-yír) \\
\hline & $\rightarrow$ le-Pér & (= le-yér) \\
\hline
\end{tabular}

$$
\begin{array}{ll}
\text { o-i-dos } \rightarrow \text { o-Pí-dos } & (=\text { o-yi-dos }) \\
\text { des-tru-ir } \rightarrow \text { des-tru-Pír } & (=\text { des=tru-yír }) \\
\text { a-Ré-e } \rightarrow \text { a-RéP-e } & \text { (= a-Réy-e }) \rightarrow \text { a-Ré-ye } \\
\text { Ri-ó } \rightarrow \text { RiP-ó } & (=\text { Riy-ó }) \rightarrow \text { Ri-yó }
\end{array}
$$

Si el acento fuera el factor determinante, para la última forma dada arriba podríamos esperar * [ Ri-Pó ] (= [Rí-wó ]), así como más temprano podríamos haber esperado únicamente "el" [ RíP-o ] ( = [ Ríy-o ] $) \rightarrow$ [ Rí-yo ],excluyendo la forma [ Rí-bo ] que en realidad ocurre. La forma [Ri-yó ] es consistente con, y paralela a, [ uP-ír ] $(=[$ uw-ír ] $) \rightarrow$ [ u-wír ], aunque éste tiene el variante [ u-Pír ] ( = [ u-yír ]).

De este estudio sobre la P epentética es posible sacar las siguientes conclusiones:

1) Para que la epéntesis ocurra, primero tiene que haberse colocado el acento de intensidad;

2) La regla 29 (que incluye la 29a y la 29b) sangra (quita las condiciones para) la regla 23 (cambio de acento de intensidad) y la regla 27 (la monoptongación). Esto permite explicar el poco número de formas encontradas como resultado de la aplicación de la regla 23 para ciertos contextos;

3) La selección de la forma de P está determinada por el rasgo $+o-[$ labial ] en una secuencia $\mathrm{VV}$ en la cual $\mathrm{V} \neq[+$ bajo ];

4) Hay una correlación, aunque incompleta, entre el acento y la selección de P;

5) El acento determina el posible cambio de [w ] $\rightarrow[\mathrm{b}] ; \mathrm{y}$,

6) Se ve una tendencia hacia la destrucción del hiato entre vocales, es decir, de un cambio de palabras polisilábicas del tipo $(\mathrm{A}) \mathrm{N}-\mathrm{N}(\mathrm{C})$ por el tipo (A)N-AN(C), en el cual $\mathrm{P}$ se interpreta como abriente cuando le sigue o le precede una vocal. 
